\title{
Strategies to Increase Parent Participation in IEP Conferences
}

\author{
SUE GOLDSTEIN \\ ANN P. TURNBULL
}

Parental involvement in the education of handicapped children has been mandated with the passage of P.L. 94-142, The Education for All Handicapped Children Act. Recent research, however, has indicated that often parents are not active decision-makers in the development of the individualized education program or IEP (Gilliam, 1979; Goldstein, Strickland, Turnbull, \& Curry, 1980).

The purpose of the study presented here was to determine the effectiveness of two intervention strategies on parental contributions to the IEP conference. The involvement strategies were: (a) sending parents questions prior to the IEP conference with a follow-up telephone call; and (b) having the school counselor present as a parent advocate at the conference.

\section{METHOD}

Forty-five parents of learning disabled children were chosen from five elementary schools in one local education agency to be observed at IEP conferences. The parents selected from each school were divided randomly into three groups. The first group of 15 parents were sent questions before the conference concerning their goals for their child, the student's educational potential, and the development of an IEP. The second group of parents had the school guidance counselor present at each conference in the role of parent advocate. No intervention strategies were used with the 15 parents in the control group.

All parents in the study were observed at their child's IEP meeting by a researcher. Speakers at the conference were coded every 30 seconds according to 13 topics. By using the coding system, the frequency and topical area of parental contributions to the conference were discerned. All parents were given a questionnaire after the conference and a researcher telephoned each parent within a week after the conference to discuss this questionnaire. The Likert scale questionnaire probed the parents' perceptions of their participation in the con- ference and parental satisfaction with the conference and its product-the IEP.

\section{RESULTS}

The mean number of relevant contributions made by parents during the IEP meeting was larger for the two groups in which an intervention strategy was employed than for the control group. One-tailed $t$ tests were computed between each group's mean number of contributions. There was no significant difference in parental involvement in the IEP conference between the parents in the control group and the parents who had been sent questions prior to the conference. There was, however, significantly more parental involvement in the conference attended by a parent advocate than in the control group $(t=2.12,28 \mathrm{df}, p<.025)$.

Analysis of the Likert scale questionnaire completed by each parent in the study found no statistical difference among the groups for either parental perception of participation or parental satisfaction.

\section{DISCUSSION}

The role of parent advocate assumed by counselors in this study did generate a greater degree of parental involvement in the IEP conference. When the counselors asked the first few questions of other committee members about the student's evaluation or progress, parents began to ask questions or comment on what they saw their child doing at home. Counselors also introduced the parents at the conference, directed questions to them, verbally reinforced their contributions, and summarized the discussion at the end of the conference.

Although the group of parents who had received questions prior to the conference did not contribute significantly more to the IEP conference than the control group, a post hoc analysis indicated that a significantly larger proportion of fathers who had received questions attended conferences. It may be conjectured that the fathers perceived the conference

Exceptional Children, Volume 48, Number 4. Copyright ${ }^{\circ} 1982$ The Council for Exceptional Children. 
as important to their child's education after reviewing the questions and decided to attend the conference. Another possible explanation is that parents receiving questions requested their spouses' participation and support, feeling that they might be outnumbered by professionals at the conference.

The results from the questionnaire indicated that all three groups of parents were satisfied with the conference and the IEP. These results were consistent with findings by Goldstein et al. (1980), in which all parents indicated satisfaction with the conference no matter what occurred during the meeting. Most parents spoke favorably about the IEP conference that they had attended, citing the fact that the meeting kept them in touch with their children's education.

In summary, the two strategies used in this study are relatively easy to implement by local education agencies and have the potential of increasing the frequency of parental input and/ or attendance by parents.

\section{REFERENCES}

Gilliam, J. E. Contributions and status rankings of educational planning committee participants. Exceptional Children, 1979, 45, 466-467.

Goldstein, S., Strickland, B., Turnbull, A. P., \& Curry, L. An observational analysis of the IEP conference. Exceptional Children, 1980, 46, 278-286.

Turnbull, A. P. Parent-professional interactions. In M. E. Snell (Ed.), Systematic instruction of the moderately and severely handicapped. Columbus OH: Charles E. Merrill, 1978.

SUE GOLDSTEIN is Director, Vance County Developmental Center, Henderson, North Carolina, and ANN P. TURNBULL is Acting Associate Director, Bureau of Child Research, University of Kansas, Lawrence.

\section{Expanded use of Captioned Films for Learning Disabled Students}

\author{
SUSAN SMITH REILLY \\ DAVID BARBER-SMITH
}

A review of research and theory on the effectiveness of multichannel media presentations in increasing recall of information suggests that if information in multiple channels is simultaneous and repetitive the amount of information received will be increased. Furthermore, the receiver will be assisted in using decoding processes to increase understanding and retention.

These conclusions point to the benefit of using captioned films for the deaf as multiple modality instructional tools for the teaching of reading skills to all sighted students with exceptional learning problems. Captioned films present information through both auditory and visual channels; content and difficulty of captions are selected for educational level; and redundancy is provided through sound, sight, reading, and action.

To determine whether a captioned film could be used to increase the word recognition skills of learning disabled students, the following exploratory project was carried out.

\section{METHOD}

A captioned film, Three Stone Blades, rated as having appeal to all ages but produced on a primary reading level, was shown to three classes; each class included seven 13- to 15year-olds with second and third grade reading levels. Twenty-five words were selected for special emphasis and were given to each student as a pretest of word recognition skills.

Class 1 saw the film twice. First, the teacher pointed to each target word as it appeared in the caption; second, the students watched the film without interference.

Class 2 read the script twice. First, the teacher stopped at the end of every sentence containing a target word and the students said it aloud, listened to the definition, and underlined it.

Exceptional Children, Volume 48, Number 4. Copyright ${ }^{\odot} 1982$ The Council for Exceptional Children. 